\title{
The Functional Role of Calcineurin in Hypertrophy, Regeneration, and Disorders of Skeletal Muscle
}

\author{
Kunihiro Sakuma ${ }^{1}$ and Akihiko Yamaguchi ${ }^{2}$ \\ ${ }^{1}$ Research Center for Physical Fitness, Sports and Health, Toyohashi University of Technology, 1-1 Hibarigaoka, Tenpaku-cho, \\ Toyohashi 441-8580, Japan \\ ${ }^{2}$ School of Dentistry, Health Sciences University of Hokkaido, Kanazawa, Ishikari-Tobetsu, Hokkaido 061-0293, Japan
}

Correspondence should be addressed to Kunihiro Sakuma, ksakuma@las.tut.ac.jp

Received 30 October 2009; Accepted 9 February 2010

Academic Editor: Henk L. M. Granzier

Copyright $\odot 2010$ K. Sakuma and A. Yamaguchi. This is an open access article distributed under the Creative Commons Attribution License, which permits unrestricted use, distribution, and reproduction in any medium, provided the original work is properly cited.

\begin{abstract}
Skeletal muscle uses calcium as a second messenger to respond and adapt to environmental stimuli. Elevations in intracellular calcium levels activate calcineurin, a serine/threonine phosphatase, resulting in the expression of a set of genes involved in the maintenance, growth, and remodeling of skeletal muscle. In this review, we discuss the effects of calcineurin activity on hypertrophy, regeneration, and disorders of skeletal muscle. Calcineurin is a potent regulator of muscle remodeling, enhancing the differentiation through upregulation of myogenin or MEF2A and downregulation of the Id1 family and myostatin. Foxo may also be a downstream candidate for a calcineurin signaling molecule during muscle regeneration. The strategy of controlling the amount of calcineurin may be effective for the treatment of muscular disorders such as DMD, UCMD, and LGMD. Activation of calcineurin produces muscular hypertrophy of the slow-twitch soleus muscle but not fast-twitch muscles.
\end{abstract}

\section{Introduction}

Calcium serves as a second messenger in signal transduction pathways, using spatiotemporal patterns of intracellular calcium to generate oscillatory changes in calcium concentrations. It is well established that the elevations in intracellular calcium levels in skeletal muscle that are essential for contractile activity also give rise to muscle-specific gene expression through downstream transcriptional pathways $[1,2]$. Changes in intracellular $\mathrm{Ca}^{2+}$ concentrations regulate the physiological activities of calmodulin. Calmodulin is a multifunctional signal transducer that undergoes conformational changes before activating a wide range of binding substrates, mainly downstream phosphatases (calcineurin) and kinases (CaMKs) [3]. The serine/threonine phosphatase calcineurin plays a major role in a variety of physiological and pathological processes, including immune responses, neuronal plasticity, and cardiac development and hypertrophy [4]. For example, transgenic mice overexpressing calcineurinA developed a profound hypertrophic responses and heart failure that mimicked human heart disease [5]. Bueno et al. [6] demonstrated that calcineurin $\mathrm{A} \beta$ null mice showed a reduced basal heart size. In addition, the absence of NFATc2 (the nuclear factor of activated T cells c2) has been shown to inhibit pathological (biomechanical stress) but not physiological (voluntary exercise training) cardiac enlargement [7]. Although the downstream pathway of calcineurin is not completely clear [8], calcineurin signaling seems to play an important role in cardiac muscle. Many excellent reviews $[8,9]$ have indicated a central role for calcineurin signaling in determining fiber types and myosin heavy chain $(\mathrm{MHC})(\mathrm{IIB} \rightarrow \mathrm{IID} \rightarrow$ IIA $\rightarrow$ I). However, few systematic and descriptive reviews have dealt with the role of calcineurin in regulating the hypertrophy and regeneration of skeletal muscle in mature mammals. This review aims to outline the functional role of calcineurin in the hypertrophy and regeneration of skeletal muscle. In addition, it discusses the present situation and future therapeutic applications for modulating calcineurin levels to alleviate muscular disorders. 


\section{Structure of Calcineurin}

Calcineurin enzymatic activity requires a catalytic subunit $(\mathrm{CnA}, 59$ to $62 \mathrm{kDa})$ and a calcium-binding regulatory subunit $(\mathrm{CnB}, 19 \mathrm{kDa})$, which comprise several isoforms coded by different genes or generated by alternative splicing. The CnA subunit includes domains for catalytic activity, CnB interaction, and calmodulin-binding. A C-terminal autoinhibitory domain, which blocks the catalytic site, is removed in response to an increase in calcium. Three calcineurin genes have been described; $\operatorname{cnA} \alpha$ and $\operatorname{CnA} \beta$ expressed ubiquitously, and $\mathrm{CnA} \gamma$ restricted to brain and testis. Two $\mathrm{CnA} \beta$ isoforms, $\operatorname{CnA} \beta 1$ and $\operatorname{CnA} \beta 2$, which differ in their C-terminal domain, are encoded by alternatively spliced transcripts [10]. The typical autoinhibitory domain present in $\operatorname{CnA} \beta 2$ and other calcineurin isoforms is absent from $\operatorname{CnA} \beta 1$, in which an unrelated C-terminal domain is generated by the translation of intronic sequences [11]. This novel domain is preserved in $\mathrm{CnA} \beta 1$ orthologues from different species [11], especially in higher vertebrates, suggesting an evolutionarily conserved role for this calcineurin variant. When activated by $\mathrm{Ca}^{2+}$-calmodulin binding, calcineurin affects gene expression by dephosphorylating specific substrates, including the four calcineurin-dependent members of NFAT gene family, NFATc1, NFATc2, NFATc3, and NFATc4. Following dephosphorylation, NFAT translocates from the cytoplasm to the nucleus and activates target genes in cooperation with other transcription factors [12]. Calcineurin activity and the ability to activate NFAT are directly antagonized by the immunosuppressive agents FK 506 and cyclosporine A (CsA) through complexes with cyclophillins and FK506-binding proteins, respectively $[13,14]$, or by endogeneous protein inhibitors, such as cain (also known as cabin-1) and MCIP1 (myocyte-enriched calcineurin interacting protein 1), the latter being particularly abundant in slow-twitch muscle but not detectable in fast-twitch glycolytic muscles $[15,16]$. More recently, reporter assays using cultured myoblasts indicated that the transcriptional activation of NFAT by calcineurin was also inhibited by calsarcin-2 [17].

\section{Muscle Regeneration}

Skeletal muscle satellite cells are generally in a quiescent state in adult muscle, but when minor damage or injury occurs, signals are generated within the muscle that activate these satellite cells, stimulating them to migrate to the site of an injury where they proliferate, differentiate, and fuse with the damaged fibers or form new fibers $[18,19]$. Studies in vitro have documented many factors, primarily protein growth factors, which can modulate satellite cell activity $[18,19]$. In particular, insulin-like growth factor I (IGF-I), whose expression is known to be upregulated in regenerating muscle in vivo [20], positively regulated the proliferation and differentiation of satellite cells/myoblasts in vitro via different pathways. Calcineurin is a major candidate for a component in the pathway downstream of IGF-I as well as Akt. In fact, the inhibition of calcineurin completely blocked the growth of myotubes on treatment with IGF-I in vitro [21]. Local expression of IGF-I in muscle protected both motor neurons and innervating muscle fibers in a mouse model of amyotrophic lateral sclerosis (the SOD1 $1^{\mathrm{G} 93 \mathrm{~A}}$ transgenic mouse) possibly due to the enhancement of $\operatorname{CnA} \beta 1$ [22]. Since activated calcineurin promotes the transcription and activation of myocyte enhance factor 2(MEF2), myogenin, and MyoD [23-25], calcineurin seems to control satellite cell differentiation and myofiber growth and maturation, all of which are involved in muscle regeneration. In fact, our previous Western blot analysis [26] showed a longterm (1-14 days post bupivacaine injection) increase in the amount of calcineurin protein in the regenerating muscle of adult rats. Immunofluorescence microscopy revealed marked immunolabeling of calcineurin in many myoblasts and myotubes that expressed MyoD and myogenin at an active differentiation phase (4-6 days post injection). In addition, our biochemical approach demonstrated that the amount of calcineurin coprecipitating with NFATc1 and GATA-2 and NFATc1 coprecipitating with GATA-2 gradually increased in the regenerating muscle. Furthermore, we showed that the inhibition of calcineurin by CsA induced extensive inflammation, marked fiber atrophy, the appearance of immature myotubes, and calcification in the regenerating muscle compared with placebo-treated mice [26]. Several other studies indicated such defects in skeletal muscle when calcineurin was inhibited [27, 28], whereas transgenic activation of calcineurin is known to markedly promote the remodeling of muscle fibers after damage $[11,29]$.

Myostatin is a member of the transforming growth factor- $\beta$ (TGF- $\beta$ ) family that negatively regulates skeletal muscle growth, with its inhibition shown to enhance muscle size. Mice, which are null for (knock-out) or display inactivating mutations of myostatin, exhibit obvious skeletal muscle hyperplasia and hypertrophy $[30,31]$. Recent evidence [32-34] has also identified myostatin as well as Id1 [22], Id3 [22], and Egr-1 [25] as a possible downstream negative hypertrophic effector target of the calcineurin-NFAT pathway. In addition, using a pharmacological approach (intraperitoneal CsA treatment), our recent study [35] demonstrated that the inhibition of calcineurin enhanced the expression of myostatin and Smad3 mRNA in regenerationdefective TA muscle after an injection of bupivacaine. An increase in myostatin levels is closely linked with muscle atrophy after unloading in mice and humans [36-38] and with severe muscle wasting in HIV patients [39]. Myostatin has been shown to interact with Smad2 and Smad3 [40, 41 , and the activation of the myostatin pathway inhibits myogenic differentiation through a downregulation of MyoD expression [40, 41]. The possibility that myostatin is a downstream mediator of calcineurin signaling has been indicated by recent experiments with two different transgenic mice [42]. Muthuri et al. [42] found that myostatin mRNA levels in skeletal muscle were significantly lower in mice expressing high levels of calcineurin and significantly higher in mice displaying inhibited calcineurin signals. Moreover, levels of calcineurin mRNA were higher in null myostatin transgenic mice than wild-type mice [42]. On the other hand, using MCK-CnA $\alpha$ transgenic mice, Stupka et al. [29] demonstrated that calcineurin activates two differentiationenhancing molecules, myogenin, and MEF2A, during muscle 
regeneration. Indeed, calcineurins pharmacological inhibition caused a decline in the transcription and activation of MEF2, myogenin and MyoD during myogenic differentiation in vitro [23-25]. However, the notion that muscle regeneration is promoted by a myogenic transgene with $\mathrm{CnA} \alpha$ is controvertial $[11,29]$. A more recent study using a similar mouse model found that transgenic expression of $\mathrm{CnA} \alpha$ excessly stimulated the inflammatory response after muscle damage and prevented prompt muscle regeneration [11].

The induction of MAFbx/Atrogin-1 expression by Foxo has been shown to inhibit calcineurin activity [43, 44]. More recently, the calcineurin variant $\mathrm{CnA} \beta 1$ was suggested to block the nuclear localization of Foxo protein and the expression of several Foxo-targeted genes (MuRF1, Gadd45a, Pmaip1, and atrogin) in C2C12 myoblasts [11]. In addition, transgenic upregulation of $\mathrm{CnA} \beta 1$ expression promoted the remodeling of cardiotoxin-treated damaged muscle fibers [11]. Foxo factors play a crucial role in skeletal muscle atrophy through the induction of MAFbx/Atrogin-1 and MuRF1 [45, 46]. Interaction between $\operatorname{CnA} \beta 1$ and Foxo in muscle regeneration is an attractive notion, although it has not been demonstrated in adult skeletal muscle in vivo.

\section{Muscle Hypertrophy}

The major extracellular mediator of skeletal muscle hypertrophy is thought to be IGF-I which binds to its receptor to initiate a cascade of signaling pathways via phosphoinositide 3-kinase (PI3-K/Akt/mammalian target of rapamycin (mTOR)) [47-49]. However, several lines of evidence suggest that IGF-I also mediates hypertrophy through calcineurin/NFAT signaling pathways. Overexpression of IGF-I in murine $\mathrm{C} 2 \mathrm{C} 12$ myoblasts [21] and rat L6MLC cells [50] induced hypertrophy of myotubes, which was abolished by treating the cells with CsA. Dunn et al. [51] proposed that calcineurin signaling regulates the hypertrophy of muscle fiber in mature rats. They concluded that the enlargement of fibers in the plantaris muscle after mechanical overloading was completely blocked at both 2 and 4 weeks post surgery by subcutaneous treatment with CsA at $25 \mathrm{mg} / \mathrm{Kg}$ twice per day. However, several lines of evidence exclude a functional role for calcineurin in the hypertrophy of muscle fiber in vivo [52-55]. For example, different to the positive effect of rapamycin, the calcineurin inhibitors CsA and FK506 for up to 30 days did not block the hypertrophy of plantaris muscle that followed surgical removal of the soleus, medial, and lateral gastrocnemius muscles in the rat [53]. Consistent with these findings, others have demonstrated that even a tenfold increase in the expression of activated calcineurin in transgenic mice did not induce muscle hypertrophy [53] in spite of an increase in the proportion of slow muscle fibers due to the influence of CnA. In addition, Parsons et al. [54] indicated that neither $\operatorname{CnA} \alpha$ nor $\operatorname{CnA} \beta$ null mice showed any growth-related alterations in skeletal muscle, and fiber size or number was not altered in glycolytic/fast muscle types (tibialis anterior, gastrocnemius, quadriceps, etc). Furthermore, no change in the size of several fast-type muscles has been observed in mice with a transgenic upregulation of calcineurin [56], although a transgenic mouse with a constitutively active form of Akt exhibited rapid and significant hypertrophy of fast-type muscles [57]. However, Talmadge et al. [56] also demonstrated that overexpression of calcineurin induced marked hypertrophy of slow-and fasttwitch fibers of the slow-type soleus muscle. In addition, fiber size in the soleus muscle was markedly reduced by a null mutation of $\operatorname{CnA} \beta$ different to $\mathrm{CnA} \alpha$ [54]. Muscle-specific overexpression of MCIP1, an inhibitor of calcineurin, using the Flox-On approach resulted in a marked reduction (about $30 \%)$ in cross-sectional area of the soleus muscle [58]. Moreover, our recent study [59] using ICR mice did not detect any apparent hypertrophy of fibers in the soleus muscle after mechanical overloading on treatment with CsA. Other researchers also suggest growth-retarded effects in the soleus muscle caused by calcineurins inhibition during recovery from hindlimb unloading [60-62]. These lines of evidence seem to indicate a selective influence of calcineurin or Akt on the size of antigravity/slow-type soleus and fasttype muscles, respectively. Table 1 shows an overview of the effect of calcineurin activation or inhibition on fiber growth (hypertrophy) of skeletal muscle in vivo.

Although calcineurin activity appears critical to mediating the hypertrophy of slow-type muscle, the downstream effector genes or targets in this process have yet to be clearly defined. Various downstream mediators of calcineuirindependent signaling have been proposed [34], including NFAT and MEF2 proteins as well as GATA transcription factors. These factors are known to costimulate the transcriptional response of certain hypertrophic marker genes in the heart $[63,64]$ and affect IGF-I-related growth of skeletal myocytes in vitro [50]. GATA-2 expression is upregulated [65] and NFAT more extensively dephosphorylated [63] in hypertrophying fast-type plantaris muscle in vivo. In addition, mice with targeted inactivation of NFATc2 or NFATc3 exhibited reduced muscle size as well as fiber type abnormalities [66] or defects in muscle formation [67], respectively. Cultured $\mathrm{C} 2 \mathrm{C} 12$ murine myoblasts expressing activated calcineurin showed increased enzymatic activity in association with NFATc3's nuclear translocation during the initiation of myogenic differentiation [23]. Given these findings, NFAT and GATA seem to play an important role in the normal growth and hypertrophy of skeletal muscle. Therefore, NFAT-GATA complexes may be mediators of calcineurin signaling during the hypertrophic process in soleus muscle. In contrast, a more recent study in our laboratory [58] suggested that MEF2C, not MEF2D or myogenin, regulates the hypertrophic process in slow-twitch soleus muscle subjected to mechanical overloading (MOV). Hypertrophy-defect soleus muscle after mechanical overloadingby calcineurin inhibition contained less MEF2C protein than a placebo-treated control. In addition, this growthfailed soleus muscle showed less extensive immunoreactivity to MEF2C in the subsarcolemmal region in a group of myotubes and/or myofibers during an active-differentiation period (4 days postsurgery) [59]. Two recent findings [68, 69] clearly showed that MEF2C is required for thick filaments to form in nascent muscle fibers and for the integrity of 
TABLE 1: Effect of calcineurin activation or inhibition on fiber growth (hypertrophy) of skeletal muscle in vivo.

\begin{tabular}{lllll}
\hline References & Species & Experimental system & $\begin{array}{l}\text { Modulating method of } \\
\text { calcineurin activity }\end{array}$ & Outcomes \\
\hline $\begin{array}{l}\text { Dunn et al. } \\
1999 \text { [51] }\end{array}$ & Mouse & $\begin{array}{l}\text { Mechanical } \\
\text { overloading }\end{array}$ & $\begin{array}{l}\text { Pharmacological inhibition } \\
\text { for 4 weeks (CsA; } 25 \mathrm{mg} / \mathrm{Kg} \\
\text { twice daily) }\end{array}$ & $\begin{array}{l}\text { Inhibition of fiber } \\
\text { hypertrophy of the plantaris } \\
\text { muscle }\end{array}$ \\
\hline $\begin{array}{l}\text { Bodine et al. } \\
2001[53]\end{array}$ & Mouse & $\begin{array}{l}\text { Mechanical } \\
\text { overloading }\end{array}$ & $\begin{array}{l}\text { Pharmacological inhibition } \\
\text { for 30 days (CsA; } 15 \mathrm{mg} / \mathrm{Kg} \\
\text { once daily) }\end{array}$ & $\begin{array}{l}\text { No inhibition of fiber } \\
\text { hypertrophy of the plantaris } \\
\text { muscle }\end{array}$ \\
\hline $\begin{array}{l}\text { Sakuma et al. } \\
2008 \text { [59] }\end{array}$ & Mouse & $\begin{array}{l}\text { Mechanical } \\
\text { overloading }\end{array}$ & $\begin{array}{l}\text { Pharmacological inhibition } \\
\text { for 2 weeks (CsA; } 25 \mathrm{mg} / \mathrm{Kg} \\
\text { once daily) }\end{array}$ & $\begin{array}{l}\text { Inhibition of fiber } \\
\text { hypertrophy of the soleus } \\
\text { muscle }\end{array}$ \\
\hline
\end{tabular}

Parsons et al. $2003[54]$

Mouse

Talmadge et
al. 2004 [56] Mouse

Talmadge et $\quad$ Mouse
al. $2004[56]$

\begin{tabular}{l}
\hline Oh et al. $2006 \quad$ Mouse \\
{$[58]$}
\end{tabular}

\begin{tabular}{|c|c|c|c|c|}
\hline & & & inhibitor (MCIP1)) & \\
\hline $\begin{array}{l}\text { Mitchell et al. } \\
2002[60]\end{array}$ & Mouse & $\begin{array}{l}\text { Reloading after } \\
\text { hindlimb } \\
\text { suspension }\end{array}$ & $\begin{array}{l}\text { Pharmacological inhibition } \\
\text { for } 2 \text { weeks }(\mathrm{CsA} ; 12.5,25 \text {, } \\
\text { and } 50 \mathrm{mg} / \mathrm{Kg} \text { once daily) }\end{array}$ & $\begin{array}{l}\text { Inhibition of fiber growth } \\
\text { (recovery) of both the soleus } \\
(25 \text { and } 50 \mathrm{mg} / \mathrm{Kg} \text { ) and } \\
\text { plantaris }(12.5,25 \text {, and } \\
50 \mathrm{mg} / \mathrm{Kg} \text { ) muscles }\end{array}$ \\
\hline $\begin{array}{l}\text { Miyazaki et } \\
\text { al. } 2006 \text { [61] }\end{array}$ & Mouse & $\begin{array}{l}\text { Reloading after } \\
\text { hindlimb } \\
\text { suspension }\end{array}$ & $\begin{array}{l}\text { Pharmacological inhibition } \\
\text { for } 4 \text { weeks (FK506; } \\
3-5 \mathrm{mg} / \mathrm{Kg} \text { once daily) }\end{array}$ & $\begin{array}{l}\text { Inhibition of fiber growth } \\
\text { (recovery) of the soleus } \\
\text { muscle }\end{array}$ \\
\hline $\begin{array}{l}\text { Oishi et al. } \\
2008 \text { [62] }\end{array}$ & Rat & $\begin{array}{l}\text { Reloading after } \\
\text { hindlimb } \\
\text { suspension }\end{array}$ & $\begin{array}{l}\text { Pharmacological inhibition } \\
\text { for } 2 \text { weeks }(\mathrm{CsA} ; 25 \mathrm{mg} / \mathrm{Kg} \\
\text { twice daily) }\end{array}$ & $\begin{array}{l}\text { Inhibition of fiber growth } \\
\text { (recovery) of the soleus } \\
\text { muscle }\end{array}$ \\
\hline
\end{tabular}

Transgenic manipulation (high-level expression of a constitutively active form of calcineurin)
Slow-twitch soleus muscle; hypertrophy (cna $\alpha \mathrm{KO}$ ), atrophy (cna $\beta \mathrm{KO}$ ), Several fast-twitch muscles (gastrocnemius, tibialis anterior, triceps brachii); no change (both cna $\alpha$ and cna $\beta$ $\mathrm{KO}$ )

Slow-twitch soleus muscle; marked hypertrophy Several fast-twitch muscles (extensor digitorum longus, tibialis anterior, plantaris); no change

(Transgenic manipulation

(Flox-On approach), upregulation of calcineurin inhibitor (MCIP1))

Atrophy of the soleus muscle

Inhibition of fiber growth plantaris $(12.5,25$, and $50 \mathrm{mg} / \mathrm{Kg}$ ) muscles Inhibition of fiber growt (recovery) of the soleus Inhibition of fiber growth muscle (recovery) of both the soleus the sarcomere and M-line during postnatal muscle growth, by directly regulating several muscle structural genes such as the genes for myomesin, MHC, and myosin light chain. Further study will be required to identify downstream modulators of calcineurin signaling during hypertrophy of slow-twitch soleus muscle. Figure 1 provides an overview of molecular pathway of calcineurin to regulate hypertrophy and regeneration of skeletal muscle.

\section{The Ameliorating Role of Calcineurin in Muscular Disorders}

Calcineurin signaling is considered to regulate the degenerative symptoms of various muscular disorders [74-84]. In animal models, pharmacological inhibition of calcineurin in regenerating muscles of young $\mathrm{mdx}$ dystrophic mice, a model of DMD, severely compromised muscle structure and function [76]. Moreover, transgenic mice overexpressing the activated form of $\mathrm{CnA}$ have been used to determine whether signaling through $\mathrm{CnA}$ improves the dystrophic pathology due to alterations in the expression of utrophin A, a therapeutically relevant protein that can compensate for the lack of dystrophin, and improved muscle membrane integrity [75]. Breeding CnA transgenic mice with $\mathrm{mdx}$ counterparts led to offspring ( $\mathrm{mdx}-\mathrm{CnA})$ with both genes altered in their skeletal muscle, but displaying a marked improvement in the dystrophic phenotype. Muscles from transgenic mdx-CnA mice showed improvements in various markers of muscle damage, including a decrease in central nucleation (indicating denervation or fiber regeneration), a decrease of variation in fiber size, a decrease in the intracellular presence of immunoglobulin $\mathrm{M}$ (a marker of 


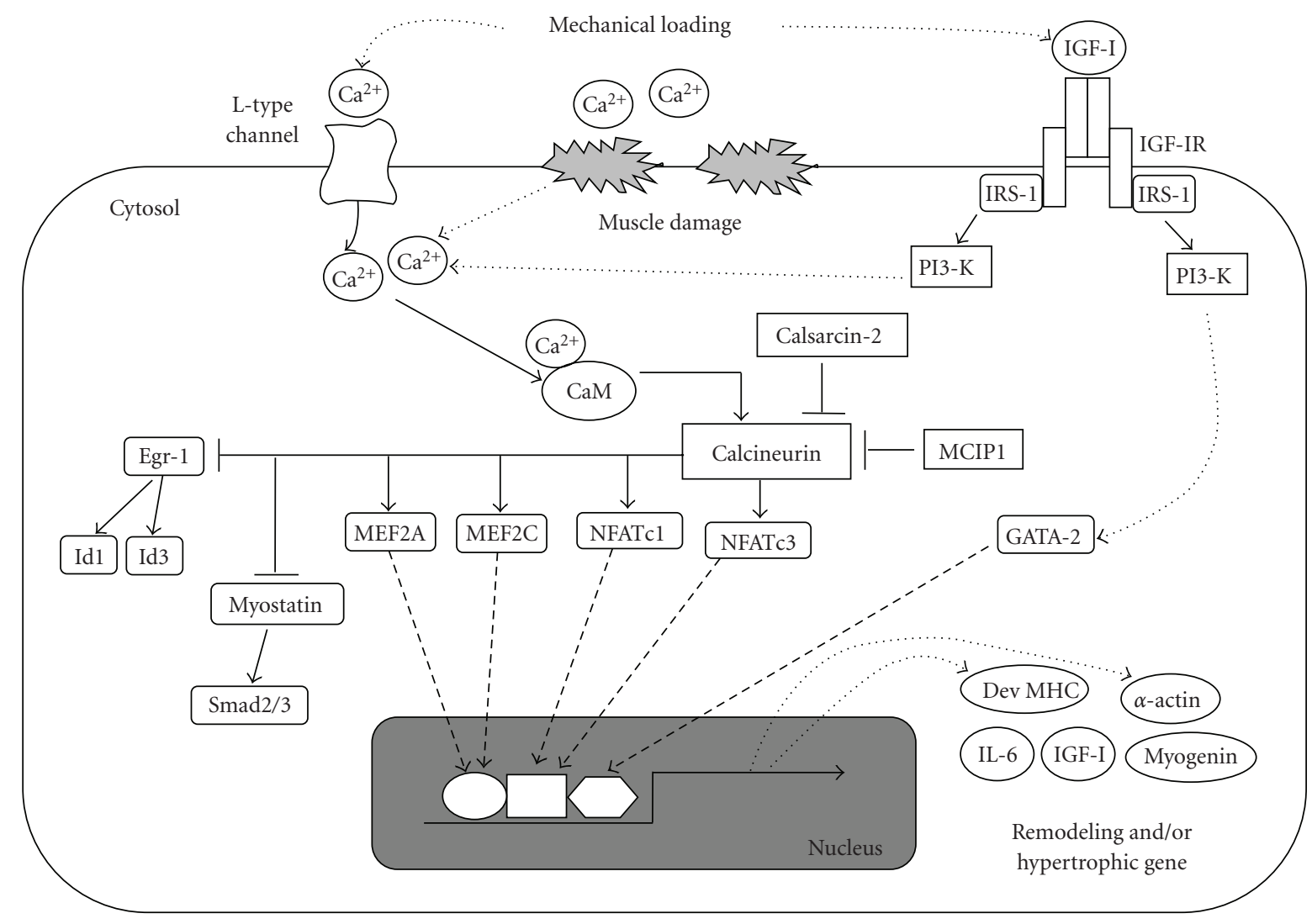

FIGURE 1: Schematic diagram of calcineurin signaling to regulate hypertrophy and regeneration of skeletal muscle. Mechanical loading of skeletal muscle increase intracellular $\mathrm{Ca}^{2+}$ levels via the influx (L-type $\mathrm{Ca}^{2+}$ channel) of $\mathrm{Ca}^{2+}$ from the extracellular space and its efflux from the sarcoplasmic reticulum. The damage of muscle fiber membrane after treatment with myotoxin also elicits an increase in intracellular $\mathrm{Ca}^{2+}$ levels via the influx of $\mathrm{Ca}^{2+}$ from the extracellular space. Binding of the $\mathrm{Ca}^{2+} / \mathrm{CaM}$ complex to the calcineurin regulatory subunit leaded to its activation. Activated calcineurin dephosphorylates NFATc1 [26, 65, 70], NFATc3 [23], MEF2C [59], and MEF2A [29, 70] resulting in their translocation from the cytoplasm to the nucleus. These transcription factors induce the expression of hypertrophic and/or remodeling genes such as Dev MHC [29], $\alpha$-actin, IGF-I [71], myogenin [25], and IL-6 [72]. In addition, activated calcineurin inhibits the functional role of Egr-1 [25] and myostatin [32-34]. Mechanical overloading upregulates gene expression of IGF-I. IGF-I modulates calcineurin signaling via increasing intracellular $\mathrm{Ca}^{2+}$ levels [25] and activating GATA-2 [50, 73]. MCIP1 [58] and calsarcin-2 [17] are potent inhibitors of calcineurin signaling. MEF2A: Myocyte enhancer factor 2A; NFATc1: nuclear factor of activated T cells c1; MCIP1: Modulatory calcineurin-interacting protein 1; IRS-1: Insulin receptor substrate-1; PI3-K: Phosphatidylinositol 3-kinase; CaM: Calmodulin; Dev MHC: Developmental myosin heavy chain; IL-6: Interleukin-6.

sarcolemmal integrity), a decrease in the uptake of Evans blue dye by muscle fibers in vivo (indicating sarcolemmal microdamage), and a decrease in numbers of infiltrating immune cells revealed by Mac-1 antibody staining (a marker of an inflammatory response) [75]. Thus, an attenuation of the muscle pathology-associated dystrophin deficiency is observed when utrophin A is upregulated via activation of CnA-NFAT signaling. In fact, Chakkalakal et al. [74] showed that calcineurin/NFATc1 signaling as well as peroxisome proliferator $\gamma$ co-activator- $\alpha$ (PGC$1 \alpha) /$ GA-binding protein $(\mathrm{GABP} \alpha)$ [77] can stimulate the transcriptional activity of utrophin A. Subsequent similar crossbreeding experiments by others $[81,83]$, leading to mdx-CnA mice with potentiated CnA-NFAT activation, showed related improvements in the contractile function and attenuation of contractile-induced injury in muscles from these animals comparted with $\mathrm{mdx}$ counterparts.
On the other hand, transgenic upregulation of the CaMbinding protein (CaMBP), a small peptide inhibitor for calmodulin, exacerbated the dystrophic phenotype in $\mathrm{mdx}$ mouse muscle. $\mathrm{mdx} / \mathrm{CaMBP}$ mice revealed an impairment of both the $\mathrm{Ca}^{2+} / \mathrm{CaM}$-regulated enzyme calcineurin and a $\mathrm{Ca}^{2+} /$ calmodulin-dependent kinase [78]. These mice exhibited significant reductions in utrophin A attributable to the marked decrease in nuclear accumulated NFATc1 and $\mathrm{MEF} 2 \mathrm{C}$ and in $\mathrm{CABP} \alpha$ mRNA expression. In contrast, pharmacological and genetic inhibition of calcineurin signaling was suggested to be effective in a mouse model and in patients with several other muscular disorders such as limb-girdle muscular dystrophy (LGMD), Ullrich congenital muscular dystrophy (UCMD), and collagen VI myopathies $[81,82,84]$. For example, in an open pilot trial, oral CsA treatment for 1 month markedly ameliorated mitochondrial dysfunction and reduced the frequency of apoptotic nuclei 
in muscle fibers in patients with collagen VI myopathies [84]. In addition, genetic deletion of the loxP-targeted calcineurin $\mathrm{B} 1$ or $\mathrm{CnA} \beta$ gene resulted in enlarged muscle fibers and decreases in the frequency of centrally nucleated fibers and of fibrosis, and in the amount of hydroxyproline in scgd $-/-$ mice [82]. These findings clearly showed that inhibition of calcineurin signaling reduced skeletal muscle degeneration and the histopathology of LGMD. Since the therapeutic effectiveness of the pharmacological attenuation or activation of calcineurin signaling differs entirely among muscular disorders, careful attention should be paid to this application.

\section{Conclusions}

This review summarised and highlighted current understanding of the role of calcineurin in the regulation of hypertrophy, regeneration, and disorders of skeletal muscle. Although several lines of evidence exclude a functional role for calcineurin in the hypertrophy of muscle fiber in vivo, recent findings have suggested that the hypertrophy of slowtwitch soleus muscle is regulated by calcineurin signaling. A possible downstream modulator of the calcineurin pathway during muscle regeneration may be MEF2A, myostatin, or Foxo. The strategy of controlling the amount of calcineurin may be effective in the future treatment of muscular disorders.

\section{Acknowledgment}

This work was supported by a research Grant-in-Aid for Scientific Research C (no. 20500575) from the Ministry of Education, Science, Culture, Sports, Science and Technology of Japan.

\section{References}

[1] D. Pette and R. S. Staron, "Cellular and molecular diversities of mammalian skeletal muscle fibers," Reviews of Physiology Biochemistry and Pharmacology, vol. 116, pp. 1-76, 1990.

[2] M. W. Berchtold, H. Brinkmeier, and M. Muntener, "Calcium ion in skeletal muscle: Its crucial role for muscle function, plasticity, and disease," Physiological Reviews, vol. 80, no. 3, pp. 1215-1265, 2000.

[3] M. B. Swindells and M. Ikura, "Pre-formation of the semi-open conformation by the apo-calmodulin C-terminal domain and implications for binding IQ-motifs," Nature Structural Biology, vol. 3, no. 6, pp. 501-504, 1996.

[4] R. A. Schulz and K. E. Yutzey, "Calcineurin signaling and NFAT activation in cardiovascular and skeletal muscle development," Developmental Biology, vol. 266, no. 1, pp. 1-16, 2004.

[5] J. D. Molkentin, J.-R. Lu, C. L. Antos, et al., "A calcineurindependent transcriptional pathway for cardiac hypertrophy," Cell, vol. 93, no. 2, pp. 215-228, 1998.

[6] O. F. Bueno, B. J. Wilkins, K. M. Tymitz, et al., "Impaired cardiac hypertrophic response in calcineurin A $\beta$-deficient mice," Proceedings of the National Academy of Sciences of the United States of America, vol. 99, no. 7, pp. 4586-4591, 2002.
[7] M. Bourajjaj, A.-S. Armand, P. A. da Costa Martins, et al., "NFATc2 is a necessary mediator of calcineurin-dependent cardiac hypertrophy and heart failure," Journal of Biological Chemistry, vol. 283, no. 32, pp. 22295-22303, 2008.

[8] J. Mallinson, J. Meissner, and K. C. Chang, "Chapter 2. Calcineurin signaling and the slow oxidative skeletal muscle fiber type," International Review of Cell and Molecular Biology, vol. 277, pp. 67-101, 2009.

[9] S. Schiaffino, M. Sandri, and M. Murgia, "Activity-dependent signaling pathways controlling muscle diversity and plasticity," Physiology, vol. 22, no. 4, pp. 269-278, 2007.

[10] D. Guerini and C. B. Klee, "Cloning of human calcineurin A: evidence for two isozymes and identification of a polyproline structural domain," Proceedings of the National Academy of Sciences of the United States of America, vol. 86, no. 23, pp. 9183-9187, 1989.

[11] E. Lara-Pezzi, N. Winn, A. Paul, et al., "A naturally occurring calcineurin variant inhibits FoxO activity and enhances skeletal muscle regeneration," Journal of Cell Biology, vol. 179, no. 6, pp. 1205-1218, 2007.

[12] G. R. Crabtree and E. N. Olson, "NFAT signaling: choreographing the social lives of cells," Cell, vol. 109, no. 2, supplement 1, pp. S67-S79, 2002.

[13] G. R. Crabtree, "Generic signals and specific outcomes: signaling through $\mathrm{Ca}^{2+}$, calcineurin, and NF-AT," Cell, vol. 96, no. 5, pp. 611-614, 1999.

[14] F. Rusnak and P. Mertz, "Calcineurin: form and function," Physiological Reviews, vol. 80, no. 4, pp. 1483-1521, 2000.

[15] R. B. Vega, B. A. Rothermel, C. J. Weinheimer, et al., "Dual roles of modulatory calcineurin-interacting protein 1 in cardiac hypertrophy," Proceedings of the National Academy of Sciences of the United States of America, vol. 100, no. 2, pp. 669-674, 2003.

[16] J. Yang, B. Rothermel, R. B. Vega, et al., "Independent signals control expression of the calcineurin inhibitory proteins MCIP1 and MCIP2 in striated muscles," Circulation Research, vol. 87, no. 12, pp. E61-E68, 2000.

[17] N. Frey, D. Frank, S. Lippl, et al., "Calsarcin-2 deficiency increases exercise capacity in mice through calcineurin/NFAT activation," Journal of Clinical Investigation, vol. 118, no. 11, pp. 3598-3608, 2008.

[18] R. Bischoff, "The satellite cell and muscle regeneration," in Myology, A. G. Engel and F. Armstrong, Eds., pp. 97-118, McGraw-Hill, New York, NY, USA, 1994.

[19] T. J. Hawke and D. J. Garry, "Myoegnic satellite cells: physiology to molecular biology," Journal of Applied Physiology, vol. 91, no. 2, pp. 534-551, 2001.

[20] E. Jennische and G. L. Matejka, "IGF-I binding and IGF-I expression in regenerating muscle of normal and hypophysectomized rats," Acta Physiologica Scandinavica, vol. 146, no. 1, pp. 79-86, 1992.

[21] C. Semsarian, M.-J. Wu, Y.-K. Ju, et al., "Skeletal muscle hypertrophy is mediated by a $\mathrm{Ca}^{2+}$-dependent calcineurin signalling pathway," Nature, vol. 400, no. 6744, pp. 576-581, 1999.

[22] G. Dobrowolny, C. Giacinti, L. Pelosi, et al., "Muscle expression of a local Igf-1 isoform protects motor neurons in an ALS mouse model," Journal of Cell Biology, vol. 168, no. 2, pp. 193199, 2005.

[23] U. Delling, J. Tureckova, H. W. Lim, L. J. De Windt, P. Rotwein, and J. D. Molkentin, "A calcineurin-NFATc3-dependent pathway regulates skeletal muscle differentiation and slow myosin heavy-chain expression," Molecular and Cellular Biology, vol. 20, no. 17, pp. 6600-6611, 2000. 
[24] B. B. Friday, V. Horsley, and G. K. Pavlath, "Calcineurin activity is required for the initiation of skeletal muscle differentiation," Journal of Cell Biology, vol. 149, no. 3, pp. 657$666,2000$.

[25] B. B. Friday, P. O. Mitchell, K. M. Kegley, and G. K. Pavlath, "Calcineurin initiates skeletal muscle differentiation by activating MEF2 and MyoD," Differentiation, vol. 71, no. 3, pp. 217-227, 2003.

[26] K. Sakuma, J. Nishikawa, R. Nakao, et al., "Calcineurin is a potent regulator for skeletal muscle regeneration by association with NFATc1 and GATA-2," Acta Neuropathologica, vol. 105, no. 3, pp. 271-280, 2003.

[27] K. L. Abbott, B. B. Friday, D. Thaloor, T. J. Murphy, and G. K. Pavlath, "Activation and cellular localization of the cyclosporine A-sensitive transcription factor NF-AT in skeletal muscle cells," Molecular Biology of the Cell, vol. 9, no. 10, pp. 2905-2916, 1998.

[28] N. Koulmann, H. Sanchez, B. N'Guessan, et al., "The responsiveness of regenerated soleus muscle to pharmacological calcineurin inhibition," Journal of Cellular Physiology, vol. 208, no. 1, pp. 116-122, 2006.

[29] N. Stupka, J. D. Schertzer, R. Bassel-Duby, E. N. Olson, and G. S. Lynch, "Calcineurin-A $\alpha$ activation enhances the structure and function of regenerating muscles after myotoxic injury," American Journal of Physiology, vol. 293, no. 2, pp. R686-R694, 2007.

[30] L. Grobet, D. Pirottin, F. Farnir, et al., "Modulating skeletal muscle mass by postnatal, muscle-specific inactivation of the myostatin gene," Genesis, vol. 35, no. 4, pp. 227-238, 2003.

[31] A. C. McPherron, A. M. Lawler, and S.-J. Lee, "Regulation of skeletal muscle mass in mice by a new TGF- $\beta$ superfamily member," Nature, vol. 387, no. 6628, pp. 83-90, 1997.

[32] K. Sakuma, R. Nakao, W. Aoi, et al., "Cyclosporin A treatment upregulates Id1 and Smad3 expression and delays skeletal muscle regeneration," Acta Neuropathologica, vol. 110, no. 3, pp. 269-280, 2005.

[33] N. Al-Shanti and C. E. Stewart, " $\mathrm{Ca}^{2+} /$ calmodulin-dependent transcriptional pathways: potential mediators of skeletal muscle growth and development," Biological Reviews, vol. 84, no. 4, pp. 637-652, 2009.

[34] R. N. Michel, S. E. Dunn, and E. R. Chin, "Calcineurin and skeletal muscle growth," Proceedings of the Nutrition Society, vol. 63, no. 2, pp. 341-349, 2004.

[35] R. N. Michel, E. R. Chin, J. V. Chakkalakal, J. K. Eibl, and B. J. Jasmin, " $\mathrm{Ca}^{2+} /$ calmodulin-based signalling in the regulation of the muscle fibre phenotype and its therapeutic potential via modulation of utrophin A and myostatin expression," Applied Physiology, Nutrition and Metabolism, vol. 32, no. 5, pp. 921929, 2007.

[36] K. Sakuma, K. Watanabe, M. Sano, I. Uramoto, and T. Totsuka, "Differential adaptation of growth and differentiation factor 8/myostatin, fibroblast growth factor 6 and leukemia inhibitory factor in overloaded, regenerating and denervated rat muscles," Biochimica et Biophysica Acta, vol. 1497, no. 1, pp. 77-88, 2000.

[37] K. Sakuma, K. Watanabe, N. Hotta, et al., "The adaptive responses in several mediators linked with hypertrophy and atrophy of skeletal muscle after lower limb unloading in humans," Acta Physiologica, vol. 197, no. 2, pp. 151-159, 2009.

[38] M. Wehling, B. Cai, and J. G. Tidball, "Modulation of myostatin expression during modified muscle use," FASEB Journal, vol. 14, no. 1, pp. 103-110, 2000.

[39] N. F. Gonzalez-Cadavid, W. E. Taylor, K. Yarasheski, et al., "Organization of the human myostatin gene and expression in healthy men and HIV-infected men with muscle wasting ," Proceedings of the National Academy of Sciences of the United States of America, vol. 95, no. 25, pp. 14938-14943, 1998.

[40] D. L. Allen and T. G. Unterman, "Regulation of myostatin expression and myoblast differentiation by FoxO and SMAD transcription factors," American Journal of Physiology, vol. 292, no. 1, pp. C188-C199, 2007.

[41] B. Langley, M. Thomas, A. Bishop, M. Sharma, S. Gilmour, and R. Kambadur, "Myostatin inhibits myoblast differentiation by down-regulating MyoD expression," Journal of Biological Chemistry, vol. 277, no. 51, pp. 49831-49840, 2002.

[42] S. K. Muthuri, E. R. Chin, and R. N. Michel, "Myostatin as a putative downstream gene target of calcineurin signaling associated with muscle growth remodeling ," FASEB Journal, vol. 21, p. 895.14, 2007.

[43] H.-H. Li, V. Kedar, C. Zhang, et al., "Atrogin-1/muscle atrophy F-box inhibits calcineurin-dependent cardiac hypertrophy by participating in an SCF ubiquitin ligase complex," Journal of Clinical Investigation, vol. 114, no. 8, pp. 1058-1071, 2004.

[44] Y. G. Ni, K. Berenji, N. Wang, et al., "Foxo transcription factors blunt cardiac hypertrophy by inhibiting calcineurin signaling," Circulation, vol. 114, no. 11, pp. 1159-1168, 2006.

[45] M. Sandri, C. Sandri, A. Gilbert, et al., "Foxo transcription factors induce the atrophy-related ubiquitin ligase atrogin-1 and cause skeletal muscle atrophy," Cell, vol. 117, no. 3, pp. 399-412, 2004.

[46] T. N. Stitt, D. Drujan, B. A. Clarke, et al., "The IGF1/PI3K/Akt pathway prevents expression of muscle atrophyinduced ubiquitin ligases by inhibiting FOXO transcription factors," Molecular Cell, vol. 14, no. 3, pp. 395-403, 2004.

[47] R. A. Frost and C. H. Lang, "Protein kinase B/Akt: a nexus of growth factor and cytokine signaling in determining muscle mass," Journal of Applied Physiology, vol. 103, no. 1, pp. 378387, 2007.

[48] D. J. Glass, "Skeletal muscle hypertrophy and atrophy signaling pathways," International Journal of Biochemistry and Cell Biology, vol. 37, no. 10, pp. 1974-1984, 2005.

[49] C. Rommel, S. C. Bodine, B. A. Clarke, et al., "Mediation of IGF-1-induced skeletal myotube hypertrophy by $\mathrm{Pl}(3) \mathrm{K} / \mathrm{Akt} / \mathrm{mTOR}$ and $\mathrm{Pl}(3) \mathrm{K} / \mathrm{Akt} / \mathrm{GSK} 3$ pathways," Nature Cell Biology, vol. 3, no. 11, pp. 1009-1013, 2001.

[50] A. Musaró, K. J. A. McCullagh, F. J. Naya, E. N. Olson, and N. Rosenthal, "IGF-1 induces skeletal myocyte hypertrophy through calcineurin in association with GATA-2 and NFATc1," Nature, vol. 400, no. 6744, pp. 581-585, 1999.

[51] S. E. Dunn, J. L. Burns, and R. N. Michel, "Calcineurin is required for skeletal muscle hypertrophy," Journal of Biological Chemistry, vol. 274, no. 31, pp. 21908-21912, 1999.

[52] F. J. Naya, B. Mercer, J. Shelton, J. A. Richardson, R. S. Williams, and E. N. Olson, "Stimulation of slow skeletal muscle fiber gene expression by calcineurin in vivo," Journal of Biological Chemistry, vol. 275, no. 7, pp. 4545-4548, 2000.

[53] S. C. Bodine, T. N. Stitt, M. Gonzalez, et al., "Akt/mTOR pathway is a crucial regulator of skeletal muscle hypertrophy and can prevent muscle atrophy in vivo," Nature Cell Biology, vol. 3, no. 11, pp. 1014-1019, 2001.

[54] S. A. Parsons, B. J. Wilkins, O. F. Bueno, and J. D. Molkentin, "Altered skeletal muscle phenotypes in calcineurin $\mathrm{A} \alpha$ and $\mathrm{A} \beta$ gene-targeted mice," Molecular and Cellular Biology, vol. 23, no. 12, pp. 4331-4343, 2003.

[55] S. A. Parsons, D. P. Millay, B. J. Wilkins, et al., "Genetic loss of calcineurin blocks mechanical overload-induced skeletal muscle fiber type switching but not hypertrophy," Journal of Biological Chemistry, vol. 279, no. 25, pp. 26192-26200, 2004. 
[56] R. J. Talmadge, J. S. Otis, M. R. Rittler, et al., "Calcineurin activation influences muscle phenotype in a muscle-specific fashion," BMC Cell Biology, vol. 5, article 28, 2004.

[57] K.-M. V. Lai, M. Gonzalez, W. T. Poueymirou, et al., "Conditional activation of Akt in adult skeletal muscle induces rapid hypertrophy," Molecular and Cellular Biology, vol. 24, no. 21, pp. 9295-9304, 2004.

[58] M. Oh, I. I. Rybkin, V. Copeland, et al., "Calcineurin is necessary for the maintenance but not embryonic development of slow muscle fibers," Molecular and Cellular Biology, vol. 25, no. 15, pp. 6629-6638, 2005.

[59] K. Sakuma, M. Akiho, H. Nakashima, et al., "Cyclosporin A modulates cellular localization of MEF2C protein and blocks fiber hypertrophy in the overloaded soleus muscle of mice," Acta Neuropathologica, vol. 115, no. 6, pp. 663-674, 2008.

[60] P. O. Mitchell, S. T. Mills, and G. K. Pavlath, "Calcineurin differentially regulates maintenance and growth of phenotypically distinct muscles," American Journal of Physiology, vol. 282, no. 5, pp. C984-C992, 2002.

[61] M. Miyazaki, Y. Hitomi, T. Kizaki, et al., "Calcineurinmediated slow-type fiber expression and growth in reloading condition," Medicine and Science in Sports and Exercise, vol. 38, no. 6, pp. 1065-1072, 2006.

[62] Y. Oishi, T. Ogata, K.-I. Yamamoto, et al., "Cellular adaptations in soleus muscle during recovery after hindlimb unloading," Acta Physiologica, vol. 192, no. 3, pp. 381-395, 2008.

[63] J. D. Molkentin, J.-R. Lu, C. L. Antos, et al., "A calcineurindependent transcriptional pathway for cardiac hypertrophy," Cell, vol. 93, no. 2, pp. 215-228, 1998.

[64] B. J. Wilkins and J. D. Molkentin, "Calcineurin and cardiac hypertrophy: where have we been? Where are we going? " The Journal of Physiology, vol. 541, no. 1, pp. 1-8, 2002.

[65] S. E. Dunn, E. R. Chin, and R. N. Michel, "Matching of calcineurin activity to upstream effectors is critical for skeletal muscle fiber growth," Journal of Cell Biology, vol. 151, no. 3, pp. 663-672, 2000.

[66] V. Horsley, B. B. Friday, S. Matteson, K. M. Kegley, J. Gephart, and G. K. Pavlath, "Regulation of the growth of multinucleated muscle cells by an NFATC2-dependent pathway," Journal of Cell Biology, vol. 153, no. 2, pp. 329-338, 2001.

[67] K. M. Kegley, J. Gephart, G. L. Warren, and G. K. Pavlath, "Altered primary myogenesis in $\mathrm{NFATC}^{-/-}$mice leads to decreased muscle size in the adult," Developmental Biology, vol. 232, no. 1, pp. 115-126, 2001.

[68] Y. Hinits and S. M. Hughes, "Mef2s are required for thick filament formation in nascent muscle fibres," Development, vol. 134, no. 13, pp. 2511-2519, 2007.

[69] M. J. Potthoff, M. A. Arnold, J. McAnally, J. A. Richardson, R. Bassel-Duby, and E. N. Olson, "Regulation of skeletal muscle sarcomere integrity and postnatal muscle function by Mef2c," Molecular and Cellular Biology, vol. 27, no. 23, pp. 8143-8151, 2007.

[70] S. E. Dunn, A. R. Simard, R. Bassel-Duby, R. S. Williams, and R. N. Michel, "Nerve activity-dependent modulation of calcineurin signaling in adult fast and slow skeletal muscle fibers," Journal of Biological Chemistry, vol. 276, no. 48, pp. 45243-45254, 2001.

[71] C. M. Alfieri, H. J. Evans-Anderson, and K. E. Yutzey, "Developmental regulation of the mouse IGF-I exon 1 promoter region by calcineurin activation of NFAT in skeletal muscle," American Journal of Physiology, vol. 292, no. 5, pp. C1887C1894, 2007.

[72] D. L. Allen, J. J. Uyenishi, A. S. Cleary, R. S. Mehan, S. F. Lindsay, and J. M. Reed, "Calcineurin activates interleukin-6 transcription in mouse skeletal muscle in vivo and in $\mathrm{C} 2 \mathrm{C} 12$ myotubes in vitro," American Journal of Physiology, vol. 298, no. 1, pp. R198-R210, 2010.

[73] A. C. Paul and N. Rosenthal, "Different modes of hypertrophy in skeletal muscle fibers," Journal of Cell Biology, vol. 156, no. 4, pp. 751-760, 2002.

[74] J. V. Chakkalakal, M. A. Stocksley, M.-A. Harrison, et al., "Expression of utrophin A mRNA correlates with the oxidative capacity of skeletal muscle fiber types and is regulated by calcineurin/NFAT signaling," Proceedings of the National Academy of Sciences of the United States of America, vol. 100, no. 13, pp. 7791-7796, 2003.

[75] J. V. Chakkalakal, M.-A. Harrison, S. Carbonetto, E. Chin, R. N. Michel, and B. J. Jasmin, "Stimulation of calcineurin signaling attenuates the dystrophic pathology in mdx mice," Human Molecular Genetics, vol. 13, no. 4, pp. 379-388, 2004.

[76] N. Stupka, P. Gregorevic, D. R. Plant, and G. S. Lynch, "The calcineurin signal transduction pathway is essential for successful muscle regeneration in mdx dystrophic mice," Acta Neuropathologica, vol. 107, no. 4, pp. 299-310, 2004.

[77] L. M. Angus, J. V. Chakkalakal, A. Mejat, et al., "CalcineurinNFAT signaling, together with GABP and PGC- $1 \alpha$, drives utrophin gene expression at the neuromuscular junction," American Journal of Physiology, vol. 289, no. 4, pp. C908-C917, 2005.

[78] J. V. Chakkalakal, S. A. Michel, E. R. Chin, R. N. Michel, and B. J. Jasmin, "Targeted inhibition of $\mathrm{Ca}^{2+} /$ calmodulin signaling exacerbates the dystrophic phenotype in mdx mouse muscle," Human Molecular Genetics, vol. 15, no. 9, pp. 1423-1435, 2006.

[79] N. Stupka, B. J. Michell, B. E. Kemp, and G. S. Lynch, "Differential calcineurin signalling activity and regeneration efficacy in diaphragm and limb muscles of dystrophic mdx mice," Neuromuscular Disorders, vol. 16, no. 5, pp. 337-346, 2006.

[80] N. Stupka, D. R. Plant, J. D. Schertzer, et al., "Activated calcineurin ameliorates contraction-induced injury to skeletal muscles of mdx dystrophic mice," Journal of Physiology, vol. 575, no. 2, pp. 645-656, 2006.

[81] A. Angelin, T. Tiepolo, P. Sabatelli, et al., "Mitochondrial dysfunction in the pathogenesis of Ullrich congenital muscular dystrophy and prospective therapy with cyclosporins," Proceedings of the National Academy of Sciences of the United States of America, vol. 104, no. 3, pp. 991-996, 2007.

[82] S. A. Parsons, D. P. Millay, M. A. Sargent, et al., "Genetic disruption of calcineurin improves skeletal muscle pathology and cardiac disease in a mouse model of limb-girdle muscular dystrophy," Journal of Biological Chemistry, vol. 282, no. 13, pp. 10068-10078, 2007.

[83] N. Stupka, J. D. Schertzer, R. Bassel-Duby, E. N. Olson, and G. S. Lynch, "Stimulation of calcineurin Aalpha activity attenuates muscle pathophysiology in mdx dystrophic mice," American Journal of Physiology, vol. 294, no. 3, pp. R983-R992, 2008.

[84] L. Merlini, A. Angelin, T. Tiepolo, et al., "Cyclosporin A corrects mitochondrial dysfunction and muscle apoptosis in patients with collagen VI myopathies," Proceedings of the National Academy of Sciences of the United States of America, vol. 105, no. 13, pp. 5225-5229, 2008. 

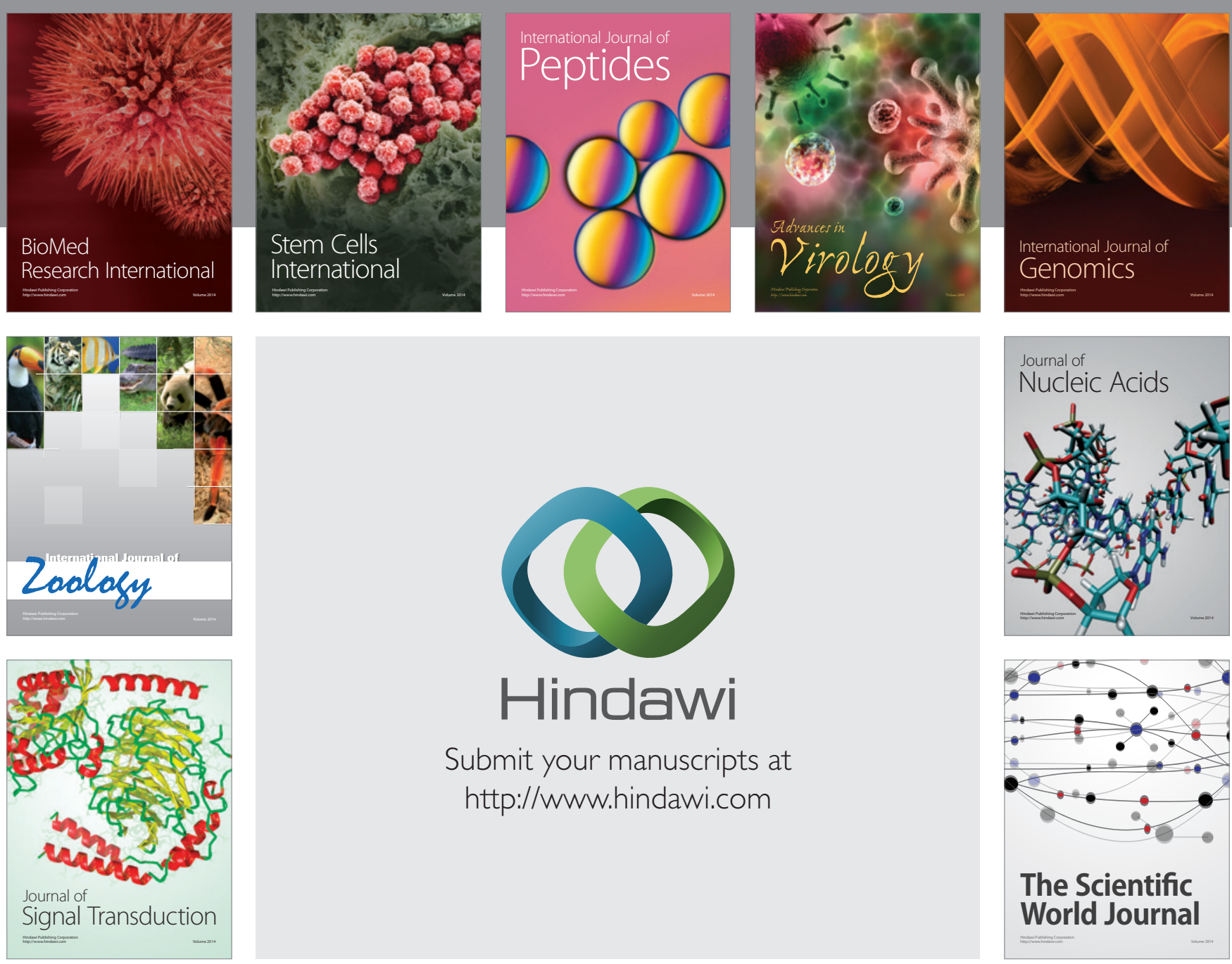

Submit your manuscripts at

http://www.hindawi.com
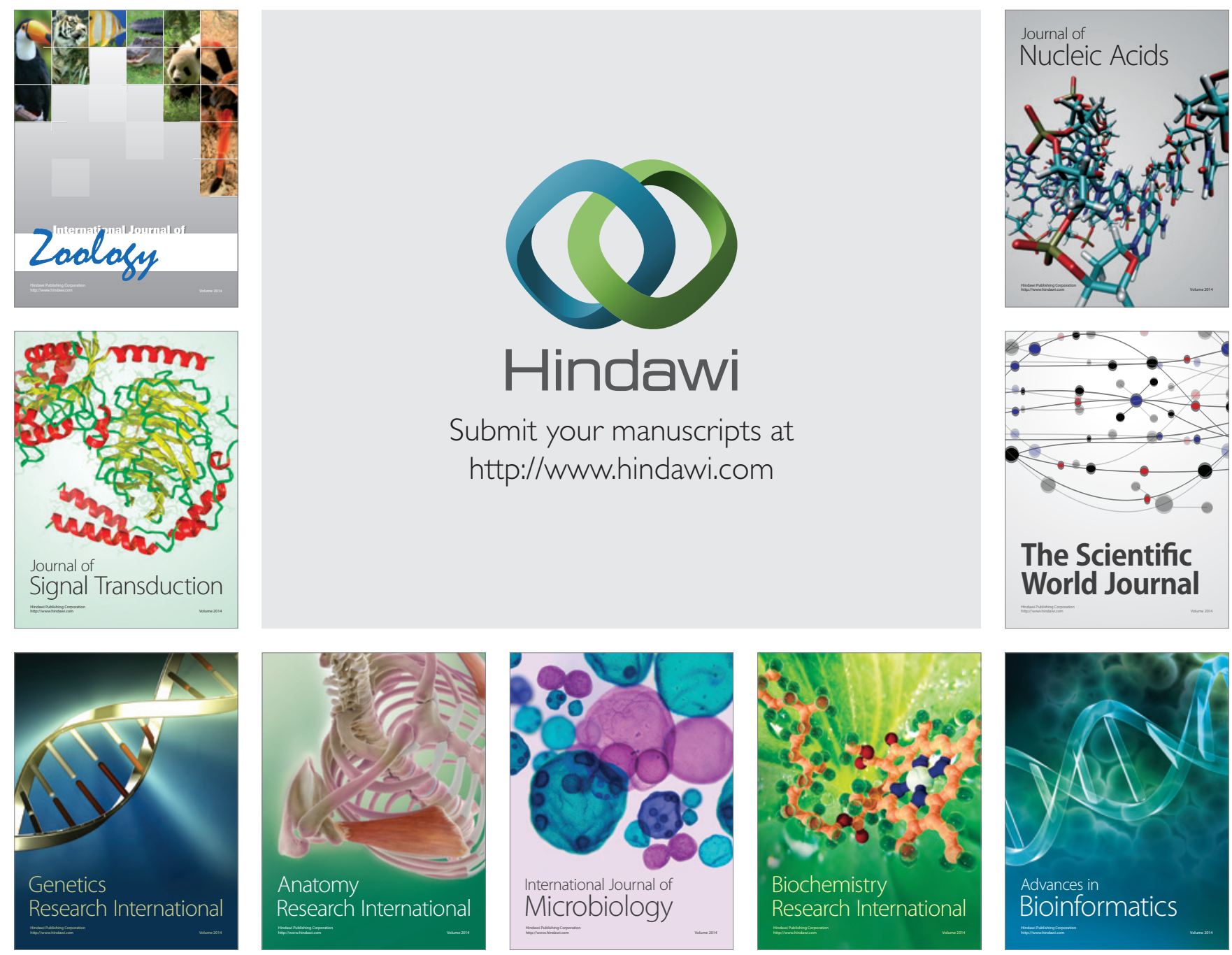

The Scientific World Journal
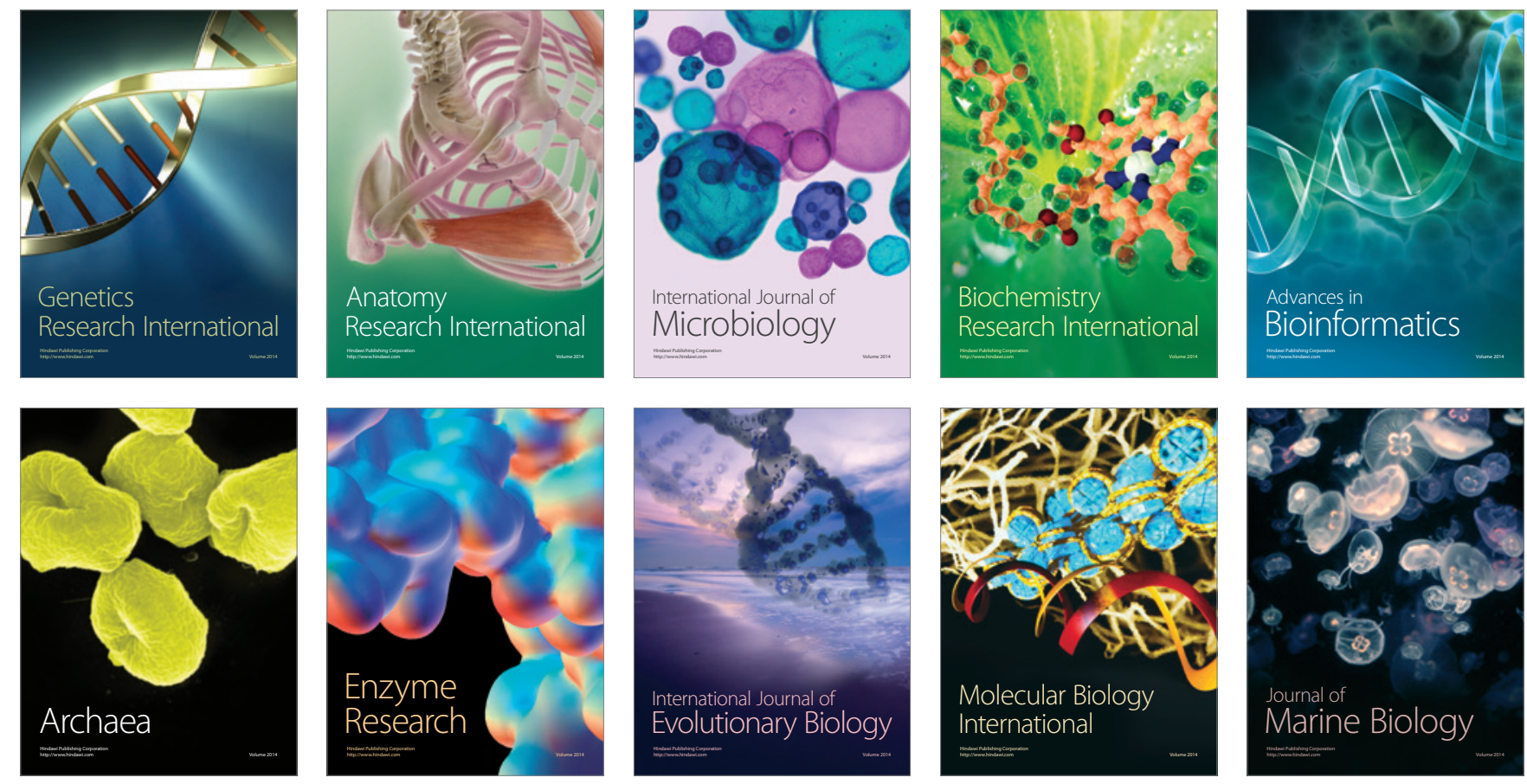